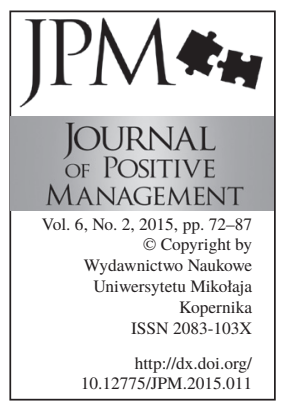

\title{
EMBEDDING SUSTAINABLE BUSINESS PRACTICE: A BETTER BUSINESS MODEL
}

\author{
Ronald Endley Ainsbury \\ Rotterdam University of Applied Sciences, \\ Research Centre Entrepreneurship and Business Innovation, Rotterdam, \\ The Netherlands \\ e-mail: r.e.ainsbury@hr.nl
}

\begin{abstract}
Purpose: The author sets out the basis for a new research programme designed to demonstrate that by encouraging managers of small to medium-sized businesses (SMEs [1]) to take a positive approach to social and environmental risks, embedding and operationalising their responses into their business strategy, they may enjoy a range of positive business benefits, as has been demonstrated by larger companies.
\end{abstract}

Approach: The author sets out an overview of recently-published research showing the wide range of business benefits that larger companies have enjoyed by embedding a positive approach to global sustainability issues, illustrating the broader studies with two high-profile examples. He posits that by encouraging managers of smaller businesses to incorporate social and environmental risks into their strategy development, they too may enjoy these business benefits.

Implications: The author suggests this positive approach will counter the current response of many SME managers - that responding to social and environmental threats will incur additional costs to their business. He advocates further research be completed to verify this hypothesis.

Keywords: social and environmental risks, sustainable business, embedding sustainable business practice, social entrepreneurship, CSR, Corporate Social Responsibility, Stages of Maturity, The Responsible Business Target, SMEs

Paper type: Viewpoint

\section{Introduction}

Several pieces of research published since 2010 have demonstrated that businesses that operationalize responsible and sustainable business practices are generating higher financial returns than those who do not.

"Responsible business is not a trade-off between people, planet and profit - companies should be expanding the connections between societal and economic progress and looking at innovative ways to integrate responsible 
business practices into their core practices. A divide is emerging between those that embrace sustainability-driven strategy and management, and those that don't. These 'embracers' are the businesses that will survive and thrive. To help those currently at an earlier stage of the journey, we need to provide the proof - the argument and numbers - that show why and how responsible business practices build successful organisations" (Business in the Community, UK 2010) [2].

It is clear that there are two broad questions that confront Business Schools in helping businesses that typically lack the resources of large multinational companies to embed sustainable business practices into their operations. Firstly, how do we reach small-to-medium-sized businesses SMEs with arguments for pursuing 'the better business model'? Secondly, how do we encourage SMEs (and entrepreneurs in general) to explore social and environmental risks as opportunities to innovate?

These questions are at the heart of my team's research programme and this paper discusses a potential line of research focusing on how smaller businesses may approach the social and environmental risks pertinent to their business as a spur to rejuvenate and innovate - addressing the challenges posed to the planet by sustainability, resource depletion and potential energy shortages in the vanguard of the 'Fourth Industrial Revolution'.

\section{Profitability or sustainability?}

The World Economic Forum states: "In the 21 $1^{\text {st }}$ century, business sustainability needs to be understood in terms of the environment, economic development, human rights, women's empowerment, and rule of law. Smart businesses are incorporating these broader principles of sustainability into their business decisions, and developing practical standards and metrics to help apply these principles in practice. These measures work to maximize opportunity and minimize the negative impact their core businesses have on the environment, the community and the economy in places where they operate". [3] This view is echoed by many.

The CEO of CalPERS, the California State Employee Pension Fund, stated that "The future will belong to innovative companies that understand that building long-term shareowner value and being an industry leader requires the integration

of sustainability principles at every level, from the $C$-suite to operations, and through the supply chain [4]".

Schumpeter, writing in The Economist, said "The new wave (sustainability) will boost their long-term competitive position, rather than their short-term profits" [5].
EMBEDDING

SUSTAINABLE BUSINESS PRACTICE

Ronald Endley Ainsbury 
EMBEDDING

SUSTAINABLE BUSINESS PRACTICE

Ronald Endley Ainsbury

\subsection{Social and environmental issues}

Since the publication of 'Limits to Growth' by the Club of Rome in 1972 [6], there has been growing interest in whether or not there will be sufficient resources, such as food, water, energy, metals and minerals, to sustain continued population and economic growth and to combat pollution.

Since 2006, the world Economic Forum has highlighted a wide range of global risks facing business and society. The 2015 Global Risks Report [7], sets out risks in five categories: Economic, Geopolitical, Environmental, Societal, and Technological.

\subsection{Businesses prefer profit}

Many followers of Milton Friedman [8] (since circa 1970) continue to advocate that businesses should focus on generating profits and not be concerned about social issues or the long term health of the planet. Rather they should focus on profit - and return surpluses to shareholders, who would then be free to support social causes if that was their wish. Arising out of this Friedmanite view came the mantra, 'maximise quarterly earnings per share'.

Many CEOs are still in the grip of short-term thinking investors. In a McKinsey survey [9] of 1.000 board members and C-suite executives [10] $86 \%$ believed that a longer-term horizon would yield positive corporate performance - financial returns and increasing innovation - but $63 \%$ said that pressure to demonstrate short-term financial performance had increased over the previous five years.

It is interesting to note that maximising short-term earnings is not a legal requirement. Statutory requirements in the USA, UK, and Australia, for example, typically require directors to make decisions "in the best interests" of the shareholders, not necessarily short-term interests.

Fortunately, at least in the UK, there appears to be a movement away from providing short-term earnings as a result of a change to the regulations [11]. The UK's Financial Conduct Authority has quietly scrapped the rule requiring public firms to release interim management statements, as part of the Government's push to encourage more long-term thinking in the stock markets. The regulator has removed the rules at the request of Vince Cable, the Business Secretary, who pledged to reduce the reporting burden on companies as recommended by Professor John Kay in 2012, who called for a culture of long-term investment rather than quick gains.

In 1997 John Elkington coined the phrase 'Triple Bottom Line' for people, planet and profit [12]. Frustratingly, almost two decades later, businesses still believe that profit comes first - then let's worry about people and the planet. A number of SME managers report they are too small to 'do CSR', that CSR is "too costly" and that "when they've grown" they will think about CSR. These were the responses the author received from Vietnamese entrepreneurs and SME 
managers at a seminar on Managing Sustainability, held in Ho Chi Minh City in 2013.

A further issue is where smaller companies are pressured by bigger customers in the supply chain to 'comply' with sustainable practices requiring more time and investment than is readily available. One Dutch, family-owned SME, visited by the author, told a story of being given a large 'Supplier Sustainability' manual by three of their multinational customers along with an instruction to "comply" and no offer of assistance or support in doing so.

In Jenkins' study [13] interviewee responses confirmed this is a widespread attitude and SMEs were somewhat cynical of being asked to demonstrate their CSR credentials by customer companies where this was perceived as part of a bureaucratic system i.e., a 'box-ticking exercise'. Their view was that customer companies should improve their own CSR before asking SMEs to demonstrate.

It may be interesting to speculate what Friedman's views might be were he alive today. The second part of his oft-quoted statement is often overlooked:

“... to make as much money as possible while conforming to the basic rules of the society, both those embodied in law and those embodied in ethical custom" [14].

We may well argue today that the basic rules of society and what society expects of business has changed.

\section{Recent research: Embedding sustainability pays off}

A number of recent studies demonstrate companies that adopt a proactive mindset and embed sustainability into their purpose and strategy demonstrate superior returns.

\subsection{Business in the Community}

In 2011, commissioned by Business in the Community, The Doughty Centre for Corporate Responsibility at the Cranfield School of Management undertook research on the business benefits of being responsible. The report [15], based on 184 unique companies, identified over 60 business benefits grouped into seven clusters:

- Brand value and reputation;

- Employees and future workforce;

- Operational effectiveness;

- Risk reduction and management;

- Organisational growth;

- Business opportunity;

- Direct financial impact. 
EMBEDDING

SUSTAINABLE BUSINESS PRACTICE

Ronald Endley Ainsbury

\subsection{Harvard}

A team at Harvard [16], Robert G. Eccles, Ioannis Ioannou, and George Serafeim, compared a matched sample of 180 companies, 90 of which they classify as High Sustainability firms and 90 as Low Sustainability firms, in order to examine issues of governance, culture, and performance. Findings for an 18-year period show that High Sustainability firms dramatically outperformed the Low Sustainability ones in terms of both stock market and accounting measures. However, the results suggest that this outperformance occurs only in the long term. Managers and investors who are hoping to gain a competitive advantage in the short term are unlikely to succeed by embedding sustainability in their organisation's strategy.

\subsection{Oxford}

A meta-study [17] of more than 190 different sources by Oxford University's Smith Institute in partnership with Arabesque Asset Management, found "a remarkable correlation between diligent sustainability business practices and economic performance". They concluded that companies with strong sustainability scores show better operational performance and are less risky. Their recommendation? "Based on the economic impact, it is in the best interest of investors and corporate managers to incorporate sustainability considerations into their decision making processes".

\subsection{Babson}

A report [18] published in 2015 concluded that "Corporate Responsibility $(C R)$ practices have great potential to deliver financial returns on investment (ROI) as well as related business and competitive benefits".

The following two high-profile stories of companies that have embedded sustainable business practices illustrates these business benefits.

\subsection{The Interface Story}

After a decade or more of learning about the product in a larger firm, an American started his own business making a variant. It is 1973. The business grew with no thought for the impact that the product's manufacture, use, or disposal might have on the environment.

"I never gave one thought to what we took from or did to the Earth, except to be sure we obeyed all laws and regulations", said the founder.

In 1994 he read a book called 'The Ecology of Commerce' by Paul Hawken and started to rethink his business. Working closely with his team he developed a new approach to making carpet and set a goal called 'Mission Zero'. 
The story of how Ray Anderson transformed his company, Interface, from what some might have described as an environmental plunderer to an environmental champion, has been well told. Ray Anderson himself wrote two books [19] and presented at a TED Conference [20].

After about 12 years of Mission Zero, Ray Anderson reported his company's progress:

- Net greenhouse gas emissions down 82 percent in absolute tonnage;

- Fossil fuel usage down 60 percent per unit of production;

- Water usage down 75 percent worldwide;

- Renewable or recyclable materials 25 percent of the total;

- Renewable energy 27 percent of total energy used;

- 74.000 tons of waste diverted from landfills (for re-use).

Even more astounding is that these welcome contributions to the environment were matched by significant improvements to the financial side of the business:

- Sales up 67\%;

- Costs down - reflecting some $\$ 400$ million dollars of avoided costs;

- Profits up $100 \%$.

These numbers might satisfy the accountants and economists. For others with an eye for people and progress, Ray's story is even more encouraging. These conclusions are from his TED talk:

- "Our people are galvanized around this shared higher purpose. You cannot beat it for attracting the best people and bringing them together";

- "Our products are the best they've ever been, inspired by design for sustainability, an unexpected wellspring of innovation";

- "The goodwill of the marketplace is astonishing. No amount of advertising, no clever marketing campaign, at any price, could have produced or created this much goodwill";

- "Costs, products, people, marketplaces - what else is there? It is a better business model"[21].

\subsection{The Unilever Story}

In 2011, Paul Polman, CEO of one of the world's largest public companies announced to the stock market that his company would no longer report on quarterly earnings. The share price fell $10 \%$. But the CEO was not concerned.

In 2010 Polman had announced the Unilever 'Sustainable Living Plan' [22]. In subsequent presentations to investors the company's senior executives set out the strategic areas of this new focus and its challenging goals:

- By 2020 Unilever will grow to double the size of the business in 2010;

- In achieving this growth goal, Unilever will decouple it's environmental impact from growth, with the aim of halving its 2010 footprint by 2020; 
EMBEDDING

SUSTAINABLE

BUSINESS PRACTICE

Ronald Endley Ainsbury

Figure 1. Unilever's Three-Pronged

Vision [23]

Figure 2. Unilever Business Benefits
- By 2020 Unilever will have had a positive impact on the lives of one billion people across the planet.

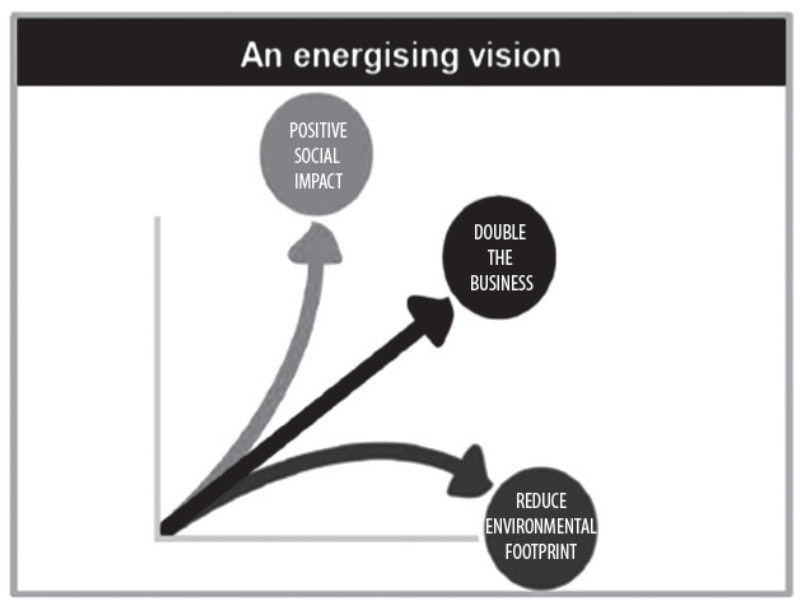

In 2015 Unilever reported [24] their progress:

- $55 \%$ of agricultural raw materials sustainably sourced;

- $0 \%$ non-hazardous waste to landfill;

- Water usage down $32 \%$ per tonne;

- Energy consumption down $37 \%$ per tonne;

- 800.000 smallholder farmers trained in improved crop management with a positive impact on their wellbeing.

Just as in the case of Interface, in achieving these remarkable outcomes in terms of social and environmental goals, Unilever reported positive financial results and multiple business benefits:

\section{Business benefits}

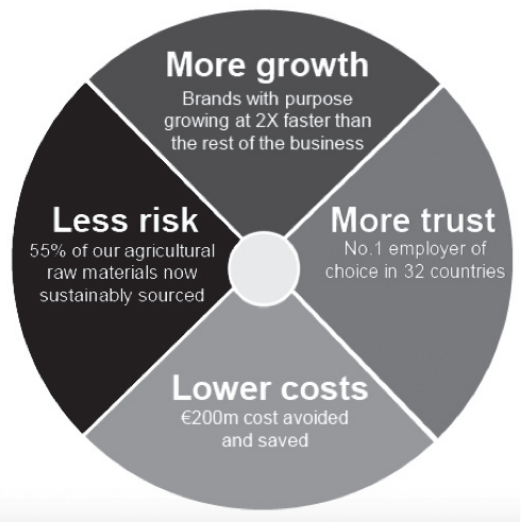


- More growth;

- More trust;

- Less risk;

- Lower costs.

\section{How can SMEs be encouraged to adopt the 'better business model'?}

How can we encourage SMEs to become more sustainable, to embed sustainable business practices into their operations? In the Research Centre we posit several steps to start the process:

- Stop using the term 'CSR';

- Evaluate all risks - economic, social, and environmental;

- Embed sustainability into the purpose of the business;

- Use innovation to turn risk into opportunity;

- Celebrate the pioneers.

\subsection{Stop using the term ' $C S R$ '}

First, let's stop referring to CSR. It is clear that the acronym itself causes confusion among managers of SMEs. This is not surprising as a Bain report [25] listed over 30 phrases used by managers as synonyms for CSR.

In a paper reporting on interviews with SMEs in the UK Jenkins reports a wide range of activities that SME managers considered 'CSR' including:

- Staff parties;

- Open house policy for customers, suppliers and competitors to look around;

- Sponsorship of local sports teams.

CSR may be limiting for two broad reasons, first the word 'corporate' immediately alienates most businesses who do not consider themselves as such. Second, 'social' implies activity outside the core business. For many, CSR implies corporate philanthropy, the very sort of activity that Friedman railed against.

\subsection{Evaluate all risks, including social and environmental}

Small businesses are already familiar with the need to evaluate the economic and technological factors that may affect them. They may also monitor their local political environment. They are fully aware that economic, technological, and political forces offer both threats and opportunities and they are quite likely to seek answers to questions such as:

- Are interest rates likely to rise or fall?

- What will be the inflation rate?

- What will be happen to personal disposable income?

- Will the incoming political party increase taxes?

- Will the government tighten emission standards? 
EMBEDDING

SUSTAINABLE

BUSINESS PRACTICE

Ronald Endley Ainsbury

Figure 3. A typical risk analysis matrix
- How will 3D printing affect my business?

- What effect will robotics have on my operations?

Some companies might even evaluate risk from time to time in a systematic way using a probability-impact matrix.

\section{Risk Rating $=$ Likelihood $x$ Severity}

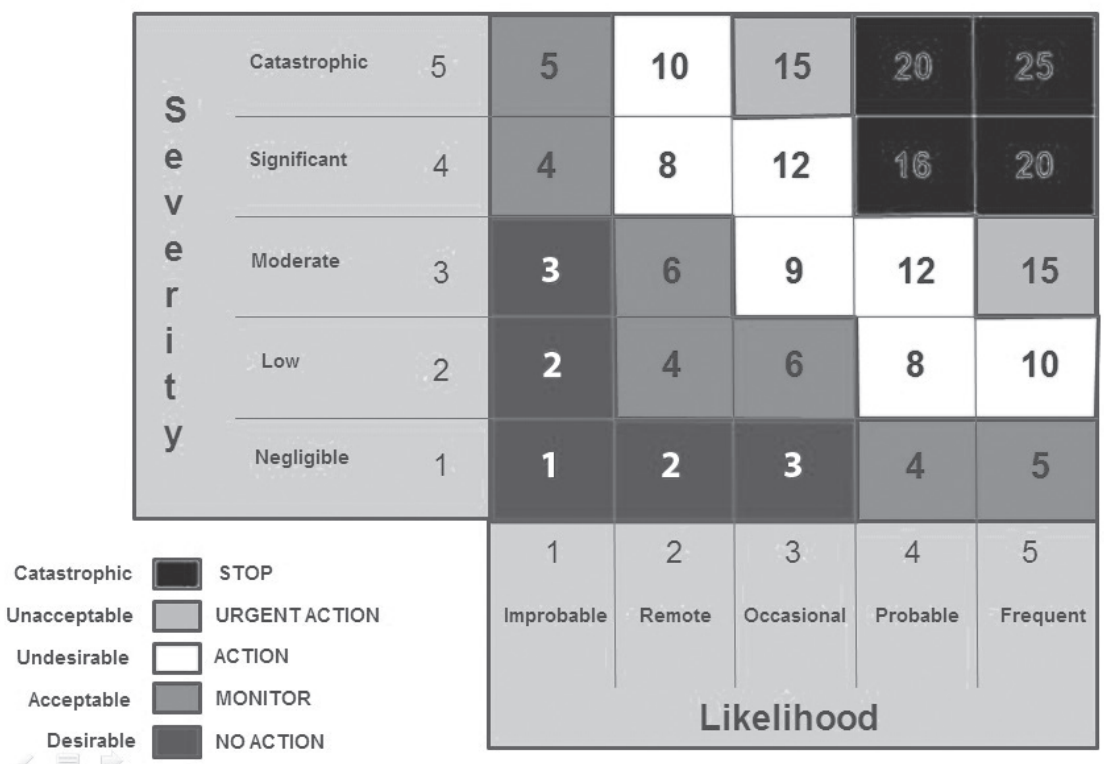

How do businesses manage economic risk?

- Evaluate the risk;

- Assess the potential impact;

- Develop a plan to mitigate, or a contingency plan, or just monitor closely;

- Seek out opportunities to take advantage of the potential change.

Social and environmental factors have the potential to have a material impact on business, as was pointed out by the Australian consultancy ECOS.

In this chart, ECOS asserts that there are social and environmental forces such as climate change and HIV/AIDS, that are acting as market forces. Couple these with global trends - such as the internet (which allows news and information to travel around the word within minutes of an event) and reducing levels of trust in governments and corporations - and every business faces changed operating conditions and potentially business value at stake. 


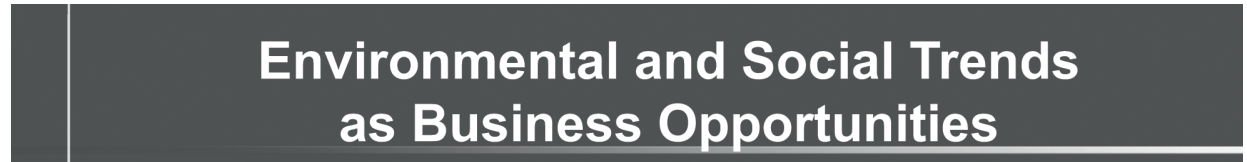

Social \& Environmental Issues as Market Forces

Climate Change

- Water Crises

- Poverty

- HIVIAIDS

- Rise in alcohol abuse

- Rise in Obesity

- Many Other Issues

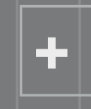

Global Trends Magnify

New Power of Civil Society

- Connectedness

- 24 hour multi-faceted media

- Globalisation

- Increasing Influence \&

Declining Trust in Corps
Changed Operating Conditions for Business

Changing Consumer Preferences

- Expectations for companies to deliver social value

- Employees expecting work aligned with their values Market Forces

- Changing Role of Gov't

\section{Business Response:}

Understand the business impact

Identify risks and seek out opportunities

Integrate Social and Environmental Trends into Business Strategy \& Decision making

Don Reed, Ecos Corporation (Australia)
EMBEDDING

SUSTAINABLE BUSINESS PRACTICE

Ronald Endley Ainsbury

Figure 4. ECOS Chart [26]

Since ECOS produced this analysis, businesses have reported multiple instances of how social and environmental risks have affected business value and caused businesses to take action. A major environmental issue is water. A survey by CDP highlighted over 850 instances of water risk being reported by over 1.000 respondents. The report set out instances where companies had been forced to make major investments to secure water supply to maintain operations including BHP Billiton investing in a desalination plant [27].

HIV/AIDS has affected businesses across the globe, particularly in Africa and not just the larger firms in that continent. As the USA's CDC points out "Small business owners understand the importance of being alert to conditions that may affect their business, their employees and their families, their customers, their community, and their bottom-line. HIV and AIDS can affect your business in many crucial ways so the more you know - the better equipped you are to protect your business" [28].

What if we ask SMEs to adopt the same process - widening their risk review to include potential social and environmental risks to their business?

- Understand the impact;

- Identify risks and opportunities;

- Integrate the response into strategy. 
EMBEDDING

SUSTAINABLE

BUSINESS PRACTICE

Ronald Endley Ainsbury

Figure 5. The Target

\subsection{Embed responses into the business - using the Target}

At Cranfield University, Prof David Grayson, building on work by David Ferguson, developed a model [29] to describe what a responsible company might look like or aspire to. Critical to the success of being responsible, is having the principles embedded in the purpose, goals, values and strategy of the business.

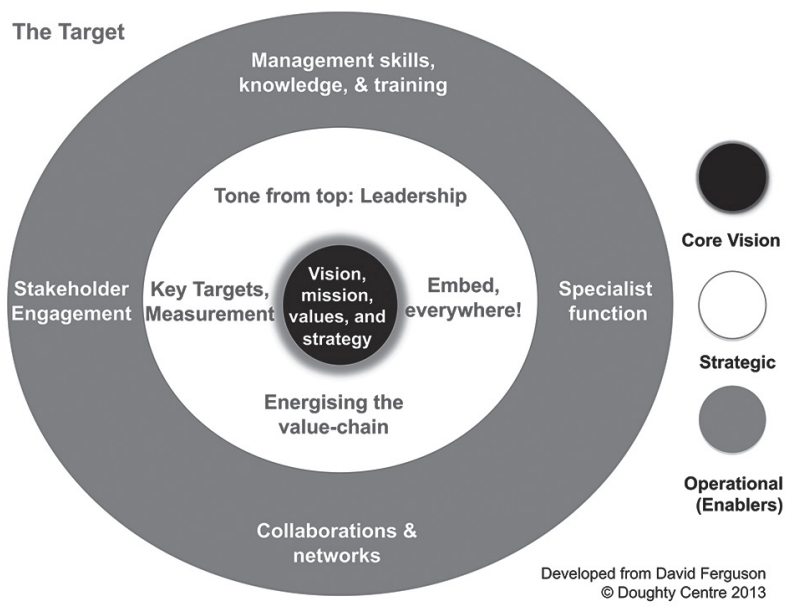

The importance of embedding a social purpose was further highlighted by research conducted for a one-day conference organized by Coca-Cola Enterprises in 2014, entitled 'Combining Profit and Purpose'. Indeed, John F. Brock, Chairman and CEO of Coca-Cola Enterprises, the largest manufacturer, distributer and marketer of Coca-Cola products in Western Europe, stated "I have been a firm advocate of two principles - that business must contribute to society and the environment; and that every investment a company makes should return value to the business. I do not believe these principles are mutually exclusive - in fact, I believe they are mutually beneficial" [30].

Many companies have now embedded sustainability or social purpose into their corporate mission or purpose. These three examples illustrate:

Campbell's Soup: "Campbell strives to promote global wellness and nutrition while building a sustainable environment and honoring our role in society from farm to the family". 
GSK: "To improve the quality of human life by enabling people to do more, feel better and live longer".

We posit that SMEs should explore how they might develop, or modify, their purpose to include an explicit reference to sustainability in one form or other their social purpose.

\subsection{Innovate!}

The Natural Edge Project [31], a consortium formed by four Australian universities, describe the 'Sixth wave of innovation' - as a new response to the challenges to the planet posed by sustainability, such as resource depletion and potential energy shortages, coupled with emerging technologies.

\section{WAVES OF INNOVATION}

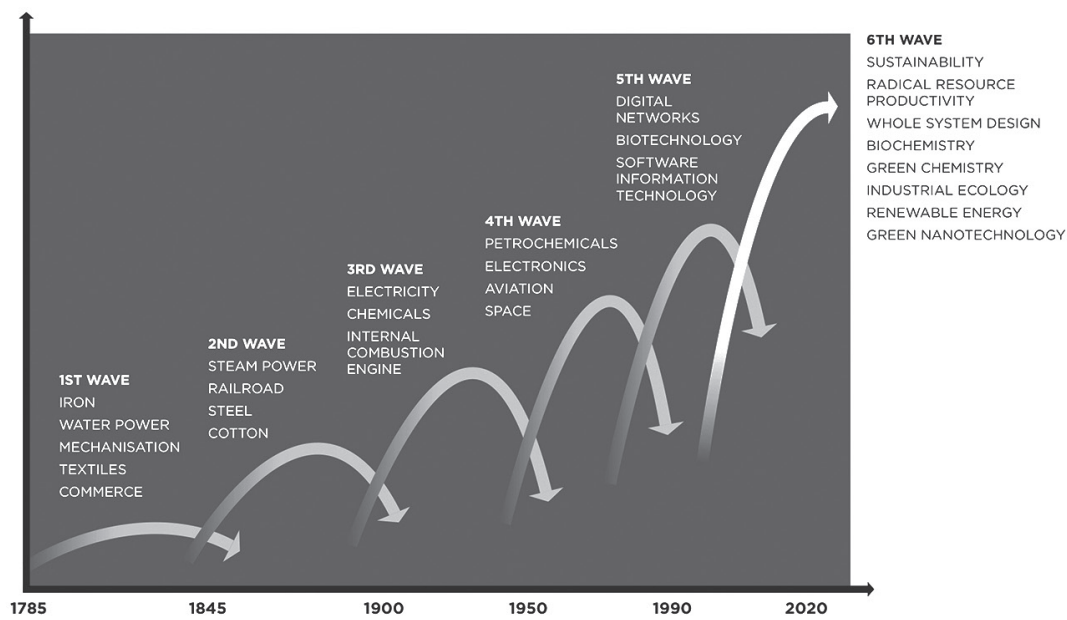

Building on this idea, the World Economic Forum and others now speak of the 'Fourth Industrial Revolution'. This concept was first proposed by the German Federal Ministry of Education and Research, "Industry now stands at the threshold of a fourth industrial revolution. Via the evolution of the Internet, the real world and the virtual world are increasingly converging, to form an "Internet of things". The key characteristics of the industrial production of the future will include production of extensively individualised products, within highly flexible
EMBEDDING

SUSTAINABLE BUSINESS PRACTICE

Ronald Endley Ainsbury
Figure 6. The Six Waves of Innovation 
EMBEDDING

SUSTAINABLE

BUSINESS PRACTICE

Ronald Endley Ainsbury

Figure 7. The

Four Industrial Revolutions [33] production environments; early-stage integration of customers and business partners within design and value-creation processes; and linking of production and high quality services, to yield "hybrid products" [32].

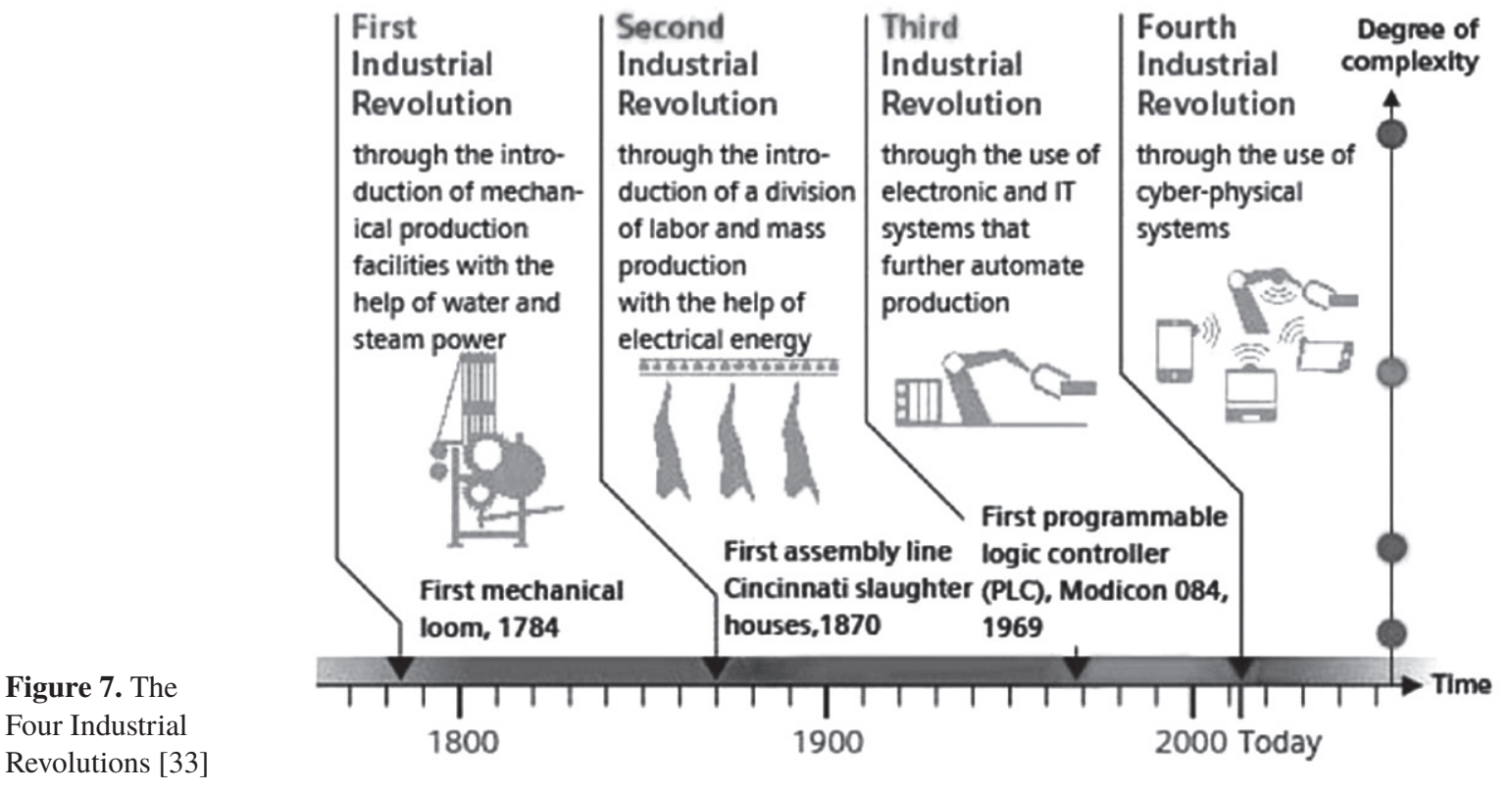

\subsection{Celebrate pioneering entrepreneurs}

Finally, we posit that publicising and celebrating pioneering entrepreneurs, who have developed innovative solutions to social and environmental risks will stimulate and encourage SME managers to explore possibilities in their own sphere of business.

There are several examples of entrepreneurs (and intrapreneurs) who have used social and environmental threats as opportunities to develop a new business or social enterprise:

While working as a journalist covering social problems, Michael Anthony [34], saw an opportunity to develop a new product, to accompany the Grameen Bank's microfinancing - microinsurance. Not only does this address a social need it has added a profitable new line of business to Allianz. And Allianz hired Michael to implement his idea.

Tristram Stuart started feeding his pigs with food waste from local shops to generate some pocket money. Then he tried feeding himself on the scraps and found that the food being dumped was highly nutritious. He started a campaign to reduce food waste which has now become worldwide. He arranged 'Feed the 
5.000' events where local chefs would provide free food to the public - all made from food that had been discarded. Today, major supermarkets are promoting 'ugly fruit' to willing customers [35].

Aly Khalifa wondered why he was getting a headache visiting a shoe factory and learned it was from the heat and volatile chemicals. He wondered - if we can put together other structures with interconnecting parts, can we do this for shoes? The answer - LYF shoes where customers design their own look, 3D print the upper and assemble - with all the components made from recycled and recyclable materials [36].

We could do more to celebrate these stories - encourage students to delve into the internet and seek out other similar examples, encourage them to consider what they might do standing on the shoulders of these giants.

\section{Conclusion}

Our Research Centre has embarked on a series of research studies to evaluate the hypotheses set out above:

1. Embedding a response to social and environmental risks into business strategy is the basis for a better business outcome.

2. Developing a social purpose provides the basis for operationalising sustainable business practices.

3. The Target is a useful tool for managers to use to ensure that their response to these risks is thorough and embedded in all aspects of their business.

4. Risks can provide the inspiration for innovation.

5. Celebrating pioneers encourages SMEs and entrepreneurs in general to innovate.

Once we have validated these hypotheses we will then start to work with business and business schools on two broad educational issues:

Q1. How can we better assist SME businesses, which typically lack the resources of large multinationals, to embed sustainable business practices into their operations and thus pursue 'the better business model'?

Q2. How do we encourage SMEs and entrepreneurs to explore social and environmental risks as opportunities to innovate?

Investing in sustainable business practices will result in SMEs improving their impact on society and the environment, attracting better and more dedicated employees, building competitive advantage through innovation and generating superior profits for their investors.

As John Kay observed [37], "Profit is no more the purpose of business than breathing is the purpose of living".
EMBEDDING

SUSTAINABLE BUSINESS PRACTICE

Ronald Endley Ainsbury 
EMBEDDING

SUSTAINABLE BUSINESS PRACTICE

Ronald Endley Ainsbury

\section{Notes and References}

[1] SME: Small, medium-sized enterprise

See http://ec.europa.eu/growth/smes/business-friendly-environment/sme-definition/index_en.htm The author believes that while the focus is on SMEs many companies that are not, by EU definition, SMEs are nevertheless targets of the interventions. Many companies, often family-owned, are larger than the limits set by EU definition, yet much smaller than the Multinationals that receive much of the public's attention.

[2] BITC, (2011), "The Business Case", available at: www.bitc.org.uk.

[3] World Economic Forum, (2014), "White Paper on Business Sustainability: What it is and why it matters", available at: www.weforum.org.

[4] Press Release by Ceres, (2012), available at: www.ceres.org.

[5] Schumpeter, (2014), "A new green wave", The Economist, August 30th 2104.

[6] Meadows, D. H., Meadows, D. L., Randers, J., Behrens III, W. W., (1972), Limits to Growth, Universe Books, New York.

[7] World Economic Forum, “Global Risks Report 2015”, available at: www.weforum.org.

[8] Friedman, M. (1970), Summed up in: "In a free-enterprise, private property system, a corporate executive is an employee of the owners of the business. He has direct responsibility to his employers. That responsibility is to conduct the business in accordance with their desires, which generally will be to make as much money as possible while conforming to the basic rules of the society, both those embodied in law and those embodied in ethical custom", The New York Times Magazine.

[9] Barton, D., Wiseman, M. (2013), "Focusing capital on the long term", McKinsey \& Company. [10] C-Suite: modern management jargon for a senior executive, typically those with Chief in their title, as in Chief Financial Officer.

[11] Daily, T., (2014), "Quarterly reporting quietly comes to an end", 15 November 2014.

[12] Elkington, J. (1997), "Cannibals with forks: the Triple Bottom Line of 21st Century Business", Capstone.

[13] Jenkins, H. (2006), "Small Business Champions for Corporate Social Responsibility", Journal of Business Ethics, Vol. 67, pp. 241-256.

[14] Friedman, M. (1970).

[15] BITC, (2011).

[16] Eccles, R. G, Ioannou, I., Serafeim, G. (2013), "The Impact of Corporate Sustainability on Organizational Processes and Performance", Harvard Business School, Working Paper 12-035.

[17] "Smith School, Oxford University and Arabesque Asset Management", "From the stockholder to the stakeholder: How sustainability can drive financial outperformance", September 2014.

[18] Rochlin, S., Bliss, R., Jordan, S., Kiser, C. Y. (2015), "Project ROI", Babson College and IO Sustainability.

[19] "Mid-Course Correction: Toward a Sustainable Enterprise: The Interface Model" (1998) by Peregrinzilla and "Confessions of a Radical Industrialist: Profits, People, Purpose: Doing Business by Respecting the Earth" (2009) by St. Martin's.

[20] TEDConference, https://www.ted.com/talks/ray_anderson_on_the_business_logic_of_sustainability.

[21] TED conference.

[22] https://www.unilever.com/sustainable-living/.

[23] https://www.unilever.com/Images/ir_Unileve-DB-June-2015-10-June_tcm244-438381.pdf.

[24] Unilever Annual Report available on www.unilever.com.

[25] Not cited for confidentiality reasons. An internal study made available to the author in preparation for a joint consulting assignment.

[26] ECOS was an Australian consulting company, since closed. The chart was kindly provided to the author by the employee who designed it, Don Reed. 
[27] CSP, "From water risk to value creation" available at www.cdp.net.

EMBEDDING

[28] http://www.cdc.gov/hiv/workplace/sbr.html.

SUSTAINABLE

[29] Grayson, D. (2012), "Overview of Embedding Corporate Responsibility", Ch 1 in "Cranfield BUSINESS PRACTICE

on Corporate Responsibility", Greenleaf.

Ronald Endley Ainsbury

[30] https://www.cokecce.com/system/file_resources/210/W21883_TL_Report_A4_FINAL.pdf.

[31] http://www.naturaledgeproject.net/.

[32] Federal Ministry of Education and Research, "The new High-Tech Strategy Innovations for Germany", 2014.

[33] DFKI - German Research Center for Artificial Intelligence.

[34] Grayson, D., McLaren, M., Spitzeck, H. (2014), Social Intrapreneurism and all that Jazz, Greenleaf.

[35] See http://www.tristramstuart.co.uk/.

[36] See http://lyfshoes.com/.

[37] "A Blueprint for Better Business", October 2014. 